\title{
The Potential Use of Nanoclayto Increa Strength of Contaminated Soil
}

\author{
Zomorodian Seyed Mohammad Ali ${ }^{1, \text { a }}$, Moghispour Shabnam ${ }^{2, \mathrm{~b}}$, Soleymani Armina, \\ ${ }^{1}$ Associate Professor, Faculty of Agriculture, Water Eng. Department, Shiraz University, Shiraz, Iran \\ ${ }^{2,3}$ Msc student, Water Eng. Department, Shiraz University, Shiraz, Iran \\ amzomorod@shirazu.ac.ir, bsmoghispour@yahoo.com, cs.armina1991@gmail.com
}

\begin{abstract}
Totally contaminated soils is known as problematic soils. Also cohesive soil with low strength is not suitable for geotechnical structures. One of the soil improvement techniques is adding an additive to soil. Given the widespread use of nanoparticles in various fields, using these materials in order to improve geotechnical properties of these soils can be a new approach. In this experimental study, the effect of adding nanoclay and curing period on strength characteristic of kerosene contaminated soil and non contaminated cohesive soil was investigated. Hence unconfined compressive strength test carried out on these two types of soil samples with different proportions of nanoclay and different curing times. The unconfined compressive strength increases significantly by adding low percent of nanoclay. For example the strength of contaminated sample was increased $297 \%$ that contained $2 \%$ nanoclay and with 28 days curing time. Keywords:Cohesive Soil; Contaminated Soil; Kerosene; Nanoclay; Unconfined Compressive Strength
\end{abstract}

\section{Introduction}

Petroleum products is the most important environmental contaminants. Contamination of soils with oil products is important not only from environmental aspect but also from geotechnical aspect. In the oil-rich countries because of the possibility of oil leakages in all processes of refining, transportation and operation are constantly exposed to oil pollution.

A large number of authors have been studied to find out changing the properties of contaminated soil by different oil pollutants. The results of studies on the impact of motor oil on the dense and loose sandy soils indicate a significant reduction in the friction angle of these soil [1] and reduction in Atterberg limits, unconfined compressive strength and also a significant increase in coefficient of permeability of clayey soil [2]. The results of study on contaminated clayey and sandy soil with crude oil, indicate a decrease in Atterberg limits, maximum dry density, permeability, optimum water content and strength [3]. For unsaturated oil contaminated sandy soil has been reported decrease of bearing capacity [4]. Alsanad and Ismael [5] carried out a laboratory tests included direct shear, triaxial, and consolidation tests to determine the effect of oil contamination and aging on the geotechnical properties of Kuwaiti sand. The results indicated increased strength and stiffness due to aging and a reduction of the oil content due to evaporation of volatile compounds. Research on the impact of kerosene on the soil showed reduction in the 
maximum dry density and increase in liquid limit [6] and initial swelling in clayey soil [7]. According to results of these studies, oil pollution has a bad effect on Geotechnical properties of soil.

Beside contaminated soils, cohesive soils are not suitable for geotechnical structures.Therefore, a finding a solution to improvement of these two types of soils is necessary. Soil improvement can decrease structure subsidence, increase bearing capacity, improve resistance, reduce swelling and enhance safety factor in sliding of embankments and dams.

One of the soil improvement techniques is adding an additive to the soil. Nanotechnology has emerged in the last decades of the twentieth century along with development of new imaging technology and simulation of substance in atomic size. Due to widespread use of nanotechnology in different science, this technologyhas been using in geotechnical recently. Also in this field of science, nanoclay has been used more than other nano materials. Researches on the effect of nanoclay on Atterberg Limits indicated increase in plasticity index of soil [8]. Effect of nanoclay on kaolinite clay and Lateritic soil, type of soil in the tropics, showed that unconfined compressive strength, plastic and liquid limits increased by adding nanoclay. Subjoining nanoclay to the two types of silty clay also represented plastic and liquid limits enhancement [9]. Results of direct shear tests have shown that shear strength of clayey soil increase by increasing nanoclay up to a certain amount [10]. Direct shear tests on silty clay contained various percentage of nanoclay indicated that by adding $2 \%$ nanoclay, enhanced cohesion to $32.2 \%$ and the angle of internal friction decreased about $17 \%$ [11]. The investigation on the effect of addition of different nano materials (nanoMgO, nanoclay and nanoCu) on geotechnical properties of Penang soft soil expressed that unconfined compressive strength increased as the increasing of nano materials content up to a certain percentage in the soil and then decreased afterwards. The maximum strength is obtained from soil that mixed with nanoclay[12].

So can be expected nanoclay has significant impact on contaminated and cohesive soils. The present work studies the strength of clean cohesive soil and impact of kerosene on strength of this soil by using unconfined compression test. Then investigates the effect of nanoclay and curing periods on the strength of these soil samples.

\section{Materials}

\section{A. Cohesive Soil}

The particle size distribution was characterized using hydrometer test. The used clay is classified as a low plastic behavior (CL) on the basis of the Unified Soil Classification System. Other soil properties of clay are given in Table 1. Also, compaction test was performed according to the standard proctor test (ASTM D 1557) to determine the maximum dry unit weight and the optimum moisture content. The result is plotted in Fig.1.

\section{B. Nanoclay (Montmorillonite}

The nanoclay particles were supplied by Sigma (American company). The size of nanoparticles was estimated to be $1-2 \mathrm{~nm}$ and its mineral constituent is montmorillonite. The specification provided by the company is given in (Table 2 and 3 ).

\section{Method}

\section{A. Unconfined Compressive Strength (UCS) Test}

Due to find out strength characteristic unconfined compressive strength tests were conducted. Through the test results cohesion (cu) of cohesive soil can be computed (Eq. 1). 


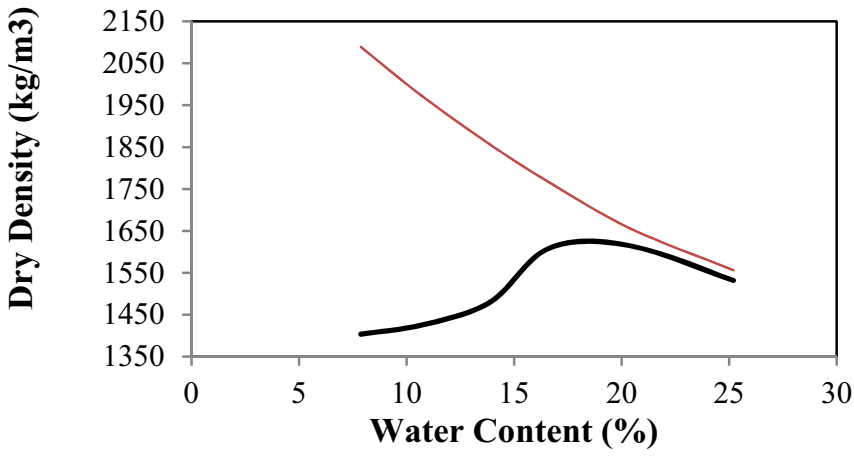

Fig. 1. Compaction curve for soil

Table 1. Properties of cohesive soil

\begin{tabular}{cc}
\hline Properties & Values \\
\hline Specific Gravity & 2.5 \\
Natural moisture (\%) & 7.8 \\
Liquid limit (\%) & 36.5 \\
Plastic limit (\%) & 17 \\
Plasticity Index (\%) & 19.5 \\
Optimum moisture content (\%) & 18.5 \\
Maximum dry density (kN/m ${ }^{3}$ ) & 16.2 \\
Soil classified (US) & $\mathrm{CL}$ \\
\hline
\end{tabular}

Table 2. Physical features of nanoclay

\begin{tabular}{cc}
\hline Properties & Value / Type \\
\hline Form & Powder \\
Specific Gravity & $3-3.7$ \\
Color & Off-White \\
Size (nm) & $01-$ Feb \\
Odor & Odorless \\
Specific surface area & $220-270$ \\
$\left(\mathrm{~m}^{2} / \mathrm{g}\right)$ & \\
Mineral & montmorillonite \\
\hline
\end{tabular}


Table 3. Chemical analysis of nanoclay

\begin{tabular}{cc}
\hline Symbol & Values $(\%)$ \\
\hline $\mathrm{Na}_{2} \mathrm{O}$ & 0.98 \\
$\mathrm{MgO}$ & 3.29 \\
$\mathrm{Al}_{2} \mathrm{O}_{3}$ & 19.6 \\
$\mathrm{SiO}_{2}$ & 50.95 \\
$\mathrm{~K}_{2} \mathrm{O}$ & 0.86 \\
$\mathrm{CaO}$ & 1.97 \\
$\mathrm{TiO}_{2}$ & 0.62 \\
$\mathrm{LOI}$ & 15.45 \\
$\mathrm{Fe}_{2} \mathrm{O}_{3}$ & 5.62 \\
\hline
\end{tabular}

$\mathrm{C}_{\mathrm{u}}=\mathrm{q}_{\mathrm{u}} / 2 .(1)$

Where qu is unconfined compressive strength and $\mathrm{Cu}$ is cohesion of cohesive soil.

\section{B. Sample Preparation}

Soil samples were dried by oven and for prepare contaminated soil samples, they were mixed with kerosene in the amount of $0,2,4,8$ and 12 percentage by dry weight of the soil samples.

To reach ionic equilibrium each samples were covered with polythene wrap and kept for about 48 hours in the cup. Then, contaminated soilsamples with $12 \%$ kerosene and non contaminated soil samples were mixed with different amount of nanoclay. To attain better mixing of nanoparticles with soil, they were dissolved in amount of optimum moisture content of soil and then were added to the soil samples.

Unconfined compressive test was conducted as ASTM-D-2166 standard for different percentages of nanoclay. All the specimens were prepared at $78 \mathrm{~mm}$ height and $38 \mathrm{~mm}$ diameter. The samples were prepared at maximum dry density and optimum moisture content. Curing time for soil samples were 1, 7, 14 and 28 days.

\section{Results and Discussions}

\section{A. Influence of Kerosene}

The results showed that as percentage of kerosene contamination increases the unconfined compressive strength of soil sample reduces (Fig.2). The results obtained in this study indicate that a minimum of strength for kerosene contaminate soil was reached in contaminated soil with $12 \%$ kerosene. The reduction is about $61 \%$ compared to the sample with $0 \%$ kerosene. So to investigate the effects of nanoclay, the soil with minimal strength is selected as the control soil.

\section{B. Effect of nanoclay on UCS}

By adding different percentages of nanoclay (NC) with 1 day curing time, the compressive strength of samplesincreased significant until a value of $1 \%$ for simple soil and $2 \%$ for contaminated soil (with $12 \%$ kerosene) and beyond which further increase in nanoclaycontent reduced the strength.It is notable that by the addition of low percent of nanoclay to the soil unconfined compressive strength increased considerably. Effect of different percentages of nanoclay on unconfined compressive strength is shown in Fig.3. 


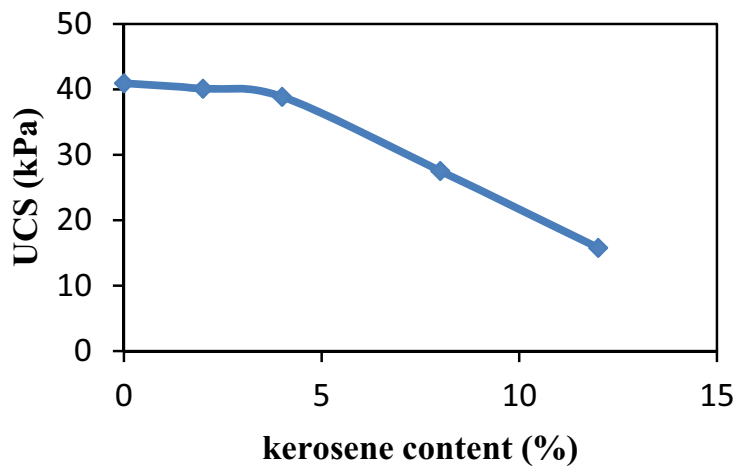

Fig. 2. Influence of kerosene on unconfined compressive strength of soil samples

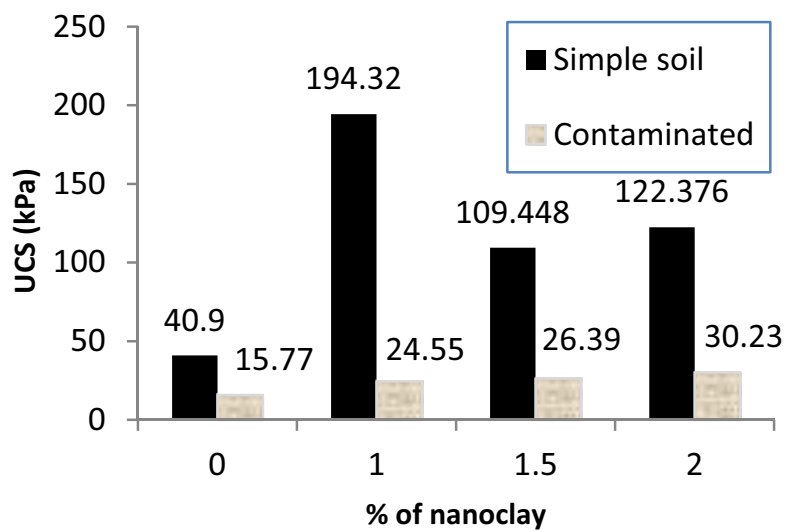

Fig. 3.Effect of nanoclay on compressive strength of soil with 1 day curing time

\section{Effect of curing time on UCS}

In order to facilitate engineering use, linear function was adopted to fit the relation between uniaxial compressive strength and curing time. The fitting results are listed in Table 4, where $\sigma$ is the uniaxial compressive strength $(\mathrm{kPa}), \mathrm{D}$ is curing time (day). The coefficient of determination, denoted as R2, indicates how close the data are to the fitted regression line, which can be obtained by (Eq. 2):

$\mathrm{R} 2=$ Explained variation / Total variation

From the fitting results in Table 4, it is concluded that there exist a very good linear relation between uniaxial compressive strength and curing time (it can found from the fact that the values of coefficient of determination of all soil samples are larger than 0.95). the uniaxial compressive strength increased dramatically as long as the curing time increased. So that samples with 28 days curing time have maximum compressive strength. According to the relation of unconfined compressive strength and cohesion (Eq. 1) it is postulated that cohesion enhanced by adding nanoclay to the soil. 
Table 4.Linear fitting results of $\sigma$ and $\mathrm{D}$

\begin{tabular}{ccc}
\hline Soil sample & Fitting function & $\mathrm{R}^{2}$ \\
\hline Simple soil without nanoclay & $\sigma=7.019 \mathrm{D}+36.73$ & 0.9989 \\
Simple soil with 1\% NC & $\sigma=9.571 \mathrm{D}+171.1$ & 0.984 \\
contaminated soil with 2\% NC & $\sigma=2.713 \mathrm{D}+37.71$ & 0.9696 \\
\hline
\end{tabular}

\section{Conclusions}

Kerosene contamination caused reduction in the unconfined compressive strength of soil which reaches $61 \%$ as compared to the control value. By adding nano materials including nanoclay to simple soil and kerosene contaminated soil, unconfined compressive strength increased. Hence using these additives can decrease structure subsidence, increase bearing capacity of soil and improve its resistance, which is important in geotechnical structures. Nanoclay as their high specific surface, have more influence on continuity of cohesive soil particles which lead to increases density and strength. It is important to note that by using a low percentage of nanoclay, good results can be achieved. Given the observed compressive strength, optimal weight percentage of nanoclay was reported $1 \%$ for non contaminated soil and $2 \%$ for contaminated soil (with $12 \%$ kerosene). Also it was specified that uniaxial compressive strength of the tested soils is related to the curing time closely. There exist very good linear relation between uniaxial compressive strength and curing time. The maximum strength of samples related to theirs with more curing time.

\section{References}

1. Evgin, E., Das, B.M., Mechanical behavior of an oil contaminated sand, Usmen, Acar (Eds.), Environ. Geotechnology Proc., Mediterranean Conference. Balkema Publishers, Rotterdam, The Netherlands.(1992) 101-108.

2. Nazir, A.K., Effect of motor oil contamination on geotechnical properties of over consolidated clay, Alexandria Engineering Journal. vol. 50, (2011) 331-335.

3. Khamehchiyan M., Charkhabi A.H., Tajik, M., Effects of crude oil contamination on geotechnical properties of clayey and sandy soils, Engineering Geology. vol. 89, (2007) 220-229.

4. Shin, E.C., Das, B.M., Bearing capacity of unsaturated oil contaminated sand, International Journal of Offshore and Polar Engineering. 11 (3),( 2001) 220-227.

5. Alsanad, H.A., Ismael, N.F., Aging effect on oil contaminated Kuwaiti sand, Journal of Geotechnical and Geo environmental Engineering.(1997) 290-294.

6. Vipulanandan, C. , Elesvwarapu, P., Index properties and compaction characteristics of kerosene contaminated clayey soil,Geo-Congress, ASCE, Geotechnics of Waste. (2008) 804-811.

7. Hamidi, A., Jedari, S., Investigating the consolidation behavior of contaminated clay, Sharif Civil Engineering Journal. vol. 29, (2011) 29-35.

8. Baziar, M., Ghazi, H. and Mir kazemi, M., Effect of nanoclay additive on properties of soil, Engineering-Geotechnical. Proc. of the 4th International Conference on Geotechnical Engineering and Soil Mechanics, ICGESM, Tehran.(2010). 
9. Bahari, M., Nikookar, M., Arabani, M., Khodaparast Haghi, A. and Khodabandeh, H., Stabilization of silt by nanoclay, In: Proceedings of the 7th National Congress on Civil Engineering, 7-8 May, Shahid Nikbakht Engineering College, Zahedan.(2013).

10. Mohammadi, M., Niazian, M., Investigation of nano-clay effect on geotechnical properties of rasht clay, International Journal Of Advanced Scientific And Technical Research. vol. 3, (2013) 37-46.

11. Badv, K. and Hossein Zadeeh, S., Effect of clay nanoclay on the geotechnical behavior of Urmia Nazlo region clay and Firoozkooh sand, Proceedings of the 8th National Conference on Civil Engineering, 6-7 May, Babol Noshirvan University of Technology.(2014).

12. Majeed, Z.H., Taha, M.R., Effect of nanomaterial treatment on geotechnicalproperties of a penang soft soil,Journal of Asian Scientific Research. 2(11),(2012)587-592. 